\title{
Deshumanización del trabajo y necesidad colectiva: consideraciones acerca del trabajo informal
}

\section{Resumen}

El comercio informal en los espacios urbanos suele ser la salida para sustentar la necesidad inmediata de sobrevivencia entre muchos obreros y campesinos que migran hacia la ciudad en busca de "mejores oportunidades". El trabajo en su expresión básica, es una implicancia práctica del movimiento bumano. El ser humano en su cotidianidad ejerce trabajo, porque emplea su cuerpo, sus manos, sus pies, sus sentidos, buscando la satisfacción de necesidad de movimiento, alimentación, bidratación, etc. En ese sentido, el trabajo no debería ser un problema mayor, sin embargo, bajo la lógica del sistema capitalista, el trabajo adquiere otra dimensión, esclaviza, explota. Este ensayo aborda el comercio informal, como un hecho laboral donde convergen relaciones sociales de poder. Se busca evidenciar que los mercados, en contextos urbanos, son espacio de conflictos, pugnas de poder provocados por la necesidad de sobrevivencia. El proceso metodológico utilizado se basa en las observaciones y notas de campo ${ }^{1}$, diarios de campo, así como la sistematización de la experiencia teórica y documental sobre el tema. Es un aporte a la discusión sobre los conflictos que con frecuencia se suscitan en estos mercados populares.

Palabras claves :Trabajo informal, relaciones de poder, lucha de clases, pequeños burgueses,

\section{Abstract}

Small business in urban area usually are the livelibood of labor and peasants who migrates to cities looking for "better opportunities." Work in its basic expression, is a practical implication of buman movement. Human being in daily life works. By uses his hands, feet, senses, seeking needs satisfaction of movements, nutrition, hidratation, etc. Thus, work should, not be great problem, however under capitalism system; work acquires another dimension, scans, exploits. This essay is about small business, as a labor fact where power relationship converge. Seeks evidence that markets in urban context are conflict spaces, power struggles caused by the need to survive. The methodological process is based on observation and field notes, also theoretical and documentary experiences systematization. It is a contribution to discuss about conflicts frequently found in these popular markets.

Keywords: small business, power relationship, class struggle, petit bourgeois

1Trabajo de campo realizado para la investigación de titulación de licenciatura: Entre tramos, carretones y canastos: identidades y relaciones sociales entre los comerciantes del mercado Oriental. 2015. UNAN-Managua. 


\section{Introducción}

Desde una perspectiva general, el trabajo se ha constituido para muchos teóricos, como el motor generador del raciocinio humano. En este sentido, se considera el trabajo como una práctica humanizadora, como proceso aplicable de la habilidad del individuo para la realización de una actividad. Un ejemplo aplicado en los análisis de Engels (1876), es la relación que hace de primates y sus habilidades para satisfacer sus necesidades básicas, haciendo uso de movimientos psicomotores, en la obtención de sus alimentos o para defenderse. Textos reconocidos como el de Althusser (1967), abona a la explicación del trabajo como proceso, siendo un indicador de desarrollo, generando habilidades y necesidad nuevas a satisfacer en un continuo.

Retomando el aspecto anterior, resulta relevante la ambigüedad que genera el ejercicio del trabajo. Cumple una función inicial para satisfacer necesidades básicas inmediatas, generando a su vez otras necesidades que apelará a otros medios para su satisfacción. Un ejemplo de ello, es la necesidad de comunicación por medio del habla y los procesos de desarrollo de lenguaje que contribuyeron a agruparse en expresiones sedentarias, en los primeros seres humanos. Contrario a lo anterior, la movilidad provoca nuevas necesidades: aprende o amplia forma de comunicación y de interrelación social.

Entendiendo la lógica del trabajo, como lo explica Engels, en la actualidad se ha dado un giro significativo sobre esta práctica. A partir de los estadíos evolutivos del ser humano, el trabajo ha trazado una línea progresiva, de sistemas económicos sociales simples, desde el comunismo primitivo al capitalismo, sin faltar expresiones más agresiva en los últimos tiempos, el neoliberalismo globalizante.

En los mercados de Managua se expresan de alguna forma, prácticas colectivas de trabajo, producto de necesidades básicas a suplir. Los miembros de familia pobres se agrupan, a partir de una organización sencilla, para la realización de una actividad mercantil informal. Este tipo de trabajo, es suplido en mercancía, por comerciantes formales, quienes tienen mejores condiciones que los primeros. La mayoría de estos comerciantes ambulantes y temporales de los mercados, trabajan de manera indirecta para este grupo formal, considerado una "elite en los mercados".

En el nivel planteado arriba, el trabajo pierde su esencia real como medio humanizante, por su incorporación en una ruta comercial, poco o nada reconocida, legal y socialmente hablando: "la informal". La gente tiene necesidad de ejercer algún tipo de trabajo que le permita la obtención de recursos para alimentarse y vestirse. La imagen que tiene el gremio de esta "élite de los mercados", de los comerciantes ambulantes o temporales, es que estos últimos, consideran, tienen comportamiento delincuenciales, cargados de antivalores; de sujetos peligros. Esta imagen colectivizada entre los compradores, genera desconfianza, haciendo que muchos busquen los establecimientos formales. La paradoja es que estos mismos comerciantes abastecen a los informales. (Narváez, 2017)

Los mercados libres (como el Oriental) se han convertidos en el "refugio" o el "mundo", como expresan los mismos comerciantes informales, de los habitantes provenientes de los barrios marginales de la sociedad. Por tanto, la necesidad de 
sobrevivencia se colectiviza, expresada esta, en las en las diversas estrategias que aplican para ganarse su sustento. El punto de inflexión está en la naturaleza del trabajo, el cargar por largas horas bolsas de agua; llevar de un lado a otro carretones llenos de mercancía, halados a manos; limpiar parabrisas de vehículos; permanecer por largo tiempo bajo el sol con productos recibido en consignación o para la "reventa", ganando la cuarta parte del valor real.

Estamos consciente el retrato que se describe, es común de los países con grandes desigualdades, como los latinoamericanos. Lo que se quiere destacar en este enfoque relacionado al trabajo, es el sesgo que se alcanza a partir de la condición de marginación, donde personas que viven y trabajan dentro de estos circuitos, estructuran su propio "mundo", diferente al normado, formalizado del 68 sistema capitalista. Es un mundo de espacios precario, sometido a la violencia de todo género con sus propias normas y regulaciones.

En este artículo se hace un acercamiento etnográfico al contexto donde se centra el estudio: el trabajo informal del Mercado Oriental. En este primer apartado se describe desde la primera persona, ese mundo al que aludimos. La idea es que el fenómeno expuesto sea percibido desde el punto de vista de un espectador. Para esta exposición, desde el punto metodológico, se recurre a un instrumento valioso, utilizado por el autor de este artículo en su trabajo: el diario de campo. En este diario, se anotaron las sensaciones y emociones del momento, cuando se realizaban las visitas al lugar.

En el segundo apartado, se realiza un análisis teórico sobre el trabajo, desde la reflexión de Engels y Marx, considerando los estadios del ser humano a partir del trabajo y las formas que este adquiere en la actualidad. El enfoque prevaleciente, acentúa el proceso de despojo y/o desarraigo de su humanidad, por medio del trabajo que realizan estas personas marginadas, llevándola al límite de sus condiciones físicas, esperanzado en agenciarse ingresos o medios para su supervivencia.

En el tercer y último apartado se realiza una reflexión sobre el trabajo informal y sus acciones deshumanizantes. En este sentido, se realiza un análisis de lo observado en el Mercado Oriental, dentro de un criterio vivencial surgido del trabajo informal, donde el esfuerzo por la sobrevivencia, los lleva a poner en riesgo su propia vida.

\section{Un día en el Mercado Oriental}

Para iniciar, me dispensan el utilizar la primera persona para abordar el tema de la compleja cotidianidad del Mercado Oriental. Este recurso, busca establecer mayor cercanía entre mi exposición y la problemática que expongo, por su naturaleza, no requiere de adornos, ni subterfugios, ella surge con descarnada realidad.

En la segunda semana de mayo del 2014, me orientaron realizar mi segundo trabajo de campo. Luego de un primer momento de reflexión acerca de lo que había encontrado, me atrapaba una nueva interrogante, ¿Qué sucede en el Mercado Oriental? ¿Por qué se ve tanta desorganización?, ¿por qué los comerciantes mantienen una actitud de confrontación entre ellos? al menos un sector con otro, aunque cada uno de estos sector está fuertemente asociado.

Era lunes, iniciaba la semana en busca de infor- 
mación interesante. El asunto era un tanto complicado. Había entrado al contexto o ambiente del mercado y los informantes que buscaba en esta ocasión, eran las autoridades administrativas, con quienes quería hablar acerca de los criterios que tenían para clasificar a los comerciantes en: fijo y ambulante.

Antes de dirigirme a las oficinas de las autoridades del Mercado, hice un recorrido de mis informantes. Pasé por el tramo de doña Chagua, comerciante de la zona uno, señora de unos cincuenta años, carismática, líderesa, dirigente en la Asociación de Comerciante de Nicaragua. Estuve con ella un rato mientras me contaba de lo interesante de ese "mundo" al que se alude en este trabajo. Lo decía con tanta elocuencia esta humilde comerciante, que ese mundo al que aludía, se representaba de manera diáfana en nuestras mentes y en cada uno de los objetos que mirábamos, dando la sensación de transportarnos a otra ciudad que no era Managua, o quizás, una al lado o debajo de la otra, como se quiera ver.

Las mismas expresiones antes citadas de doña Chagua, me recordaba uno de mis primeros encuentros con otros informantes. En algunas ocasiones ellos hacían referencia a ese "mundo" de los comerciantes de estos mercados, como un escenario aislado, socialmente hablando, imaginado que únicamente toma vida en sus acciones colectivas. Esto me recordó las consideraciones de los antropólogos urbanos Manuel Castells (1972) y Hannerz (1987) quienes sustentan la tesis de estos mercados, como expresiones de una ciudad dentro de otras ciudades.

Doña Chagua insistía en que pusiera atención a los diálogos entre los comerciantes, las expresio- nes que utilizaban, impregnadas, la mayor parte de ellas, de confianza y cohesión entre los grupos. Aunque en los diálogos, se intercalaban palabras, consideradas obscenas dentro del establishment urbano formal, era (y sigue siendo) de uso común entre ellos, sin que resulte ofensa alguna. Los comerciantes ambulantes, entre "amigos" se lanzan improperios, pero dentro de un ambiente de camaradería. No así con otras personas pertenecientes a otros grupos con los cuales no se tiene el mismo nivel de confianza o familiaridad, pudiendo desembocar en conflictos.

Mientras escuchaba a doña Chagua, su voz se confundía con otras voces provenientes de los alrededores, en un coro disonante de ofertas de productos: "que vas a querer amor", "llévate tomates, frescos tomates". La estrategia se develaba sencilla: convencer al potencial comprador, utilizando recursos verbales y gestuales sutiles. A quienes no les gusta que lo trataran con frase amorosas, reaccionan cuando el vendedor intercala frases que apelan a la sociabilidad y al comercio, describiendo el producto con sus supuestas atribuciones. Al cabo de un rato, mientras seguía en el tramo de doña Chagua, ubicado muy cerca de la Estación 1 de la policía; llega una amiga de ella, a quien me presenta, ofreciéndose a acompañarme en el recorrido por el Mercado.

Mientras hablábamos a media y entre cortado, debido a la dificultad de caminar en medio de tramos, mercancías de todo tipo sobre los andenes y calles, el sol del mediodía y el calor sofocante, hacía que aligeráramos el paso. Llegamos al Gancho de Camino, una referencia popular del mercado, esquina arriba, subimos tres cuadras, desembocando en una calle libre de tramos y mercancía, con mucho tránsito. Giramos a la izquierda y con- 
tinuamos caminando sobre una calle abarrotada de tramos de electrodomésticos, al final de la misma llegamos a la esquina "Power 0.99", tienda de árabes. Tomamos a la derecha y al fondo de esta divisé el árbol de limonaria, donde permanecen habitualmente, un guarda de seguridad o un policía, en esta ocasión estaba un policía sentado en una silla de plástico.

Por fin llegamos a COMMEMA. En el portón les solicité a los guardas de seguridad entrar para conversar con el asistente del Gerente. Sin mucho trámite llegué hasta el despacho del Asistente, quien sin abandonando cualquier protocolo -si existía-me orientó con quien abocarme para conseguir mi información y continuar con mi investigación: los Vice gerentes.

Las oficinas de estos funcionarios están ubicado en otro lugar de donde estaba. El mercado está dividido para fines administrativo y comercial, en tres zonas. Tres Vice gerentes atienden cada una de estas zonas, por esta razón, se tuvo que ir a tres lugares diferentes. La zona 1 concentra el comercio de ropa y zapatos y electrodomésticos en general; la zona 2, carne, abarrotes, y de especias; y la zona 3 perecederos y alguno tramos de mariscos, la cual es compartida con la zona 2.

La señora que me acompaño hasta COMMEMA se había ido sin darme cuenta. Una de las primeras decisiones que tomé, en ese momento, fue visitar a cada uno de los Vice gerentes, comenzando por el de la zona 1. Durante el trayecto, me encontré con tramos de diversos tamaños, surtidos de una variedad de productos. Una de las características de trabajo en estos tramos formales, es que en ellos laboran varios muchachos o muchachas, bajo un tipo de contrato verbal, cuyo pago se da por hora trabajada o por temporada, pactando un salario. Lo que no se pacta y queda a discreción de la dueña, es la entrada y salida en cada jornada laboral, generando flagrantes abusos.

En cada uno de los callejones de la zona 1 encontré al menos un vendedor ambulante que halaba un carretón con productos diversos, refrescos, agua helada, verduras. Sorteando filas de gente que van y vienen, en esos callejones angostos, muchos de ellos no descansan en su camino, apelando a la comprensión de cada uno de los compradores: "cuidado". En algunos casos usan el humor para solicitar el paso: "el golpe avisa". Su recorrido es casi infinito, sin rumbo establecido, les guía la multitud de gente en cada callejón, deteniéndose sólo cuando le solicitan un producto.

El contacto con ellos, durante la investigación, me permitió saber que pese al duro trabajo de halar un carretón con mucho peso durante todo el día, logran reunir unos cuantos pesos que les permite suplir las necesidades de día en su "hogar". El trabajo diario con el carretón trae consecuencia con el tiempo, padeciendo de problemas lumbares y de columna. La postura inclinada a la que se habitúa, los encorva, siendo llamados por sus amigos con el sobrenombre de "cuco".

La dinámica de trabajo del vendedor de carretón, no se diferencia mucho de otros vendedores ambulantes que llevan sus productos en la cabeza o los hombros. Todos ellos deambulan en los callejones del Mercado, pasan sol, empujones, y sufren de los mismo males de salud; de igual manera, se conocen y saben sus virtudes y debilidades. Forman grupos siguiendo algunos principios de solidaridad cultivados a la luz de alguna desgracia, lugares de procedencia o vicios compartidos. 
Por otro lado, cargan la imagen de potenciales delincuentes o pandillero, con razón o no, pero ellos no se arredran, defienden su mundo y su forma de ganarse la vida. Aunque hay sus excepciones, vendedores que aspiran y luchan por migrar de ese ambiente del Mercado.

Durante el trayecto que hice hasta la zona 1, interactué con los vendedores de los tramos, quienes me halagaban tomándome del brazo para que me detuviera y entrara a ver los productos que ofertan. Ellos hacen todo lo posible para que no repares a ver otros tramos, ni otras ofertas. Siempre me he preguntado, si el performance que hacen para seducir al potencial comprador, es intuitivo, ensayado o discutido previamente con el propietario del tramo.

Después de caminar por cierto tiempo, cruzando tramos, llegué a la oficina del Vice gerente de la zona 1. Para mi infortunio, no encontré al funcionario edilicio. Durante ese momento de espera, di unas vueltas, sin percatarme en la misma zona. Un comerciante me hizo ver mi error, al interpelarme de una manera enfática, "si era un ladrón". Ante mi desconcierto, volvió a preguntar, esta vez de manera concreta: "que andaba buscando, porque miraba raro que diera tantas vueltas cerca de su tramo". Me repuse de mi sorpresa, explicándole mi propósito. Hizo una cara de comprensión, para luego orientarme el camino de la oficina del Vice gerente de la zona 2, hacia donde pensaba ir, luego del viaje fallido a la zona 1.

La Vice gerente de la zona 2, era una dama, y me fue difícil encontrar su oficina. Las orientaciones del comerciante fueron exactas y llegue sin problema. Sentí alivio de encontrarla y atenderme de manera rápida. Contestó las preguntas que llega- ba. Tuvo la gentileza de delegar al guarda de seguridad para que me llevara a la zona 3, propiamente donde estaba la sede de la Vice Gerencia. Tomó esa decisión argumentando que era una de las zonas más peligrosas del Mercado.

Durante mi recorrido, debo destacar ciertas características observadas en cada una de las zonas visitadas. En la zona 1 el ambiente, la disposición de los tramos, el tipo de mercancía (electrodomésticos, zapatos, telas, juguetes, entre otros), y la aglomeración de vendedores, disputándose al cliente que pasa en los callejones, como en un hervidero, generé agitación y agilice el paso de la gente en su recorrido. En la zona 2 donde se expenden carnes y especias, los olores son diversos y la forma de ofertar los productos está revestida por un aire casero, familiar. No es la actividad agitada y casi atropellada de la zona 1 , sino de cierta tensa tranquilidad, producto de la particularidad de la disposición del producto, en ganchos o pinzas, y el uso de herramientas corto punzante. En la zona 3 el ambiente cambia de manera sustancial con respecto a las dos zonas anteriores, el ambiente se enrarece producto de una combinación de olores de verduras o frutas remaduras, o descompuestas con tramos de mariscos, que colindan con la zona 2. Se siente cierto tono lúgubre, pero relajado, subvertido en gran medida por hombres, vestidos hasta la cintura, sin camisas o con camisolas y chanclas o chinelas.

Mientras caminaba hacia la zona tres, pasó por mi lado una muchacha de unos 25 años (calculo, según sus facciones físicas), ella llevaba un carretón un poco pequeño, vendía gaseosa y agua helada. El carretoncito compuesto por dos cajones en la parte del extremo alejado de ella, se ubica la primera caja donde lleva estos productos, en la otra 
que está pegada a la primera pero al lado de la muchacha va un niño de un año de edad más o menos.

Donde iba colocada el niño estaba acomodado con una acumulación de trapos, estos trapos en su mayoría de ropa vieja, son los más fáciles de conseguir en ese espacio. Sin embargo aunque la escena es desafortunada, la misma era apurada o rechazada por quienes estaban en un tramo o quienes también andaban vendiendo el mismo producto, claro porque no importa la condición de la persona, sino que todos andan bajo la lógica de vender y todos necesitan vender, sea cual sea la condición.

Mientras caminaba a la zona 3, encontré tramos pequeños, personas más desaliñadas que otras, niños sucios y un grupo de hombres tatuados. Estaban sentados en una esquina, cerca de unos baños públicos y salas de juegos. Esta escena atemoriza a cualquiera, aligeré el paso y llegué a otra zona con mayor afluencia de compradores. Esta imagen es la que se reproduce en los medios de comunicación creando una visión negativa sobre el mercado, específicamente sobre ese sector (Narváez, 2017).

Una cosa es cierta, la realidad del mercado retrata aquello que la gente desprecia, las condiciones inadecuadas de vida. Mucha gente que vende en este Mercado, realiza todas las actividades personales en este lugar. Otros tienen este lugar como su hogar. Sin duda, la situación de precariedad de estas personas, se debe a factores diversos que confluyen, entre ellos, acceso a educación, ambiente familiar inestable, adicciones, entre otros.

\section{Aproximación teórica al trabajo}

Engels (1876) en su obra sobre el papel del trabajo en el proceso de transformación del mono en hombre, incorpora un elemento importante para el análisis del trabajo y su aporte transformador: el uso de las manos. Este hecho, da origen al desarrollo del individuo. Por tanto, el trabajo como producto de la necesidad, resultó ser útil para el sistema locomotor del cuerpo. El hombre transforma el medio en el que se desenvuelve, al mismo tiempo que él también cambia y evoluciona biológica y culturalmente.

Marx (1976) desde su enfoque materialista infiere en que el trabajo llega en un momento en que la humanidad se "humanizaba" por medio del ejercicio sistemático y consciente de esa actividad. Los individuos se han adaptado a sistemas complejos que los han hecho avanzar, dentro de una lógica hegemónica, marcada por concepciones, necesidades básicas, e intercambio (Comunismo primitivo, Esclavismo, Feudalismo, Capitalismo).

Bajo esta lógica de "desarrollo" y avance del ser humano y por supuesto de las manifestaciones del trabajo, se implementan capacidades de agrupamiento, estrategia de normalización de leyes y reglas, como parte de la evolución misma de las sociedades. Esto genera una contradicción inherente a la forma del trabajo en su concepción inicial y como mecanismo de dominación.

Siguiendo esta lógica, el trabajo es un proceso en el que el individuo se da cuenta que necesita agruparse y de esa forma se crean pequeñas sociedades (Giddens, 1991). Esta se evidencia con el proceso de dominación, por parte del hombre, de la naturaleza. El mismo hombre se vuelve parte de esa cultura de la dominación, individualista, sobre 
los medios de producción. Esto último es explicado en Marx (1976) y Engels (1974), señalando, la contradicción del trabajo como medio humanizador y fuente para solventar las necesidades básicas, al tiempo que es acumuladora de riqueza (hay que recordar el doble valor de la mercancía que Marx lo planteó en El Capital: valor de uso y valor de cambio): Durante el proceso de producción los hombres no sólo crean los productos materiales para su propia subsistencia, sino que simultáneamente producen y reproducen sus relaciones sociales (Burlatski, 1982; p. 22).

Partiendo de la idea anterior, se puede fundamentar que el otro es dominado producto del giro que se le dio al valor del trabajo. Proceso iniciado a partir de las sociedades primitivas. En distintos estudios de ramas diversas de la ciencias humanas, se analizan las formas en que el capitalismo ha hegemonizado las prácticas relacionadas con el trabajo, explotando en distintos momento, y con una variedad de mecanismos, a la mayor parte de los seres humanos, exclavizados por el sistema.

Es propio señalar, como lo indican los estudios hechos sobre la evolución humana (Bordes, 1968; Burlatski, 1982; Mark y Hobsbawm, 1979; Petit, et.al., 1978 y Harris, 1982), el hombre domina la naturaleza, al tiempo que siente la necesidad, y busca la forma de dominar a los seres humanos que le rodean. En distinto momento de la historia, por la división social del trabajo y el control de los medios de producción, se verá como el "otro" dominado. Por tanto, quien acumula desea reproducir su capital, por ello necesita mano de obra, fuerza de trabajo, y esa condición de poder, le lleva a crear mecanismos de coerción, muchos de ellos sutiles, revestidos de legalidad y "aceptados" por la mayoría.
La dominación y relaciones de poder se expresan de diferentes formas y niveles. Para este trabajo, se parte del análisis de las relaciones de poder que se dan durante el trabajo realizado a lo interno de los mercados abiertos, populares de las ciudades (en este caso el Mercado Oriental de Managua). El trabajo en los puestos informales tiene un carácter de sobrevivencia, inscrito dentro de una estructura de subordinación. Esta situación se da cuando existe un vínculo comercial entre los proveedores que cuentan con recursos y los vendedores, convirtiéndose, de hecho en empleados de ellos.

El propietario de bienes que opera en los mercados dentro de la "formalidad" comercial, necesita quien le venda su mercancía, por eso realiza contrato con los vendedores ambulantes, informales. Este tipo de trabajo no se rige por los mecanismos legales establecidos por el Estado. El que realiza esta labor esta desprotegido en términos de salud y de cualquier prestación o demanda. Es un trabajo precario, de sobrevivencia del "otro". En este ejercicio, es que se da la dominación y/o subordinación de parte del propietario que suple mercancía a los que se comprometen a trabajar bajo ese régimen. En caso que no cumpla con el pago de la mercancía al final del día, o el día pactado, estos comerciantes tienen sus formas coercitivas de cobrarlo. Ellos nunca pierden. Esta dinámica de trabajo los adultos la transmiten a sus hijos, muchos de estos acompañan al vendedor ambulante, convirtiéndose en un círculo vicioso.

La antropóloga Larissa Lomnitz (1976), infiere que en los grupos marginados, el trabajo es la expresión de la necesidad de sobrevivencia colectivizada entre los miembros del barrio. Esta situación, genera agrupamientos, estructura redes de 
socialización para el trabajo, de cualquier tipo, u otras actividades que les asegure la supervivencia de los miembros.

\section{Trabajo informal y necesidad de sobrevivencia}

En el contexto nicaragüense, el trabajo y comercio informal son fuentes de sobrevivencia de un porcentaje sustantivo de personas, habitantes muchas de ellas, de las zonas urbanas más deprimidas, en términos de calidad de vida. Es habitual que en las plazas y calles de la ciudad, se encuentren grupos de personas, de diferentes edades y sexo, vendiendo algún producto que los transeúntes o conductores demandan eventualmente, siendo este un medio para "ganarse la vida", como ellos repiten.

Es un hecho que estos vendedores lo hacen por necesidad. Algunas familias que se dedican a la venta, producen o cultivan algún producto el cual venden, haciendo un cálculo del precio, donde se pueda obtener utilidades, y continuar produciendo. Existen situaciones extremas, de personas que visitan lugares donde las empresas, en el caso de lácteos, arrojan algunos desechos, recogidos por estas personas, quienes lo reciclan y lo venden en forma de cuajada o cajetas de leche. Lo común es la venta ambulante, adquiriendo productos en consignación por el día, en la mayor parte de los casos; en otros casos, los jóvenes son contratados como cargadores o limpiadores.

Forma parte de la dinámica cotidiana de estos mercados populares, la presencia masiva de comerciantes informales, que laboran sin tiempo y sin ninguna medida de protección, manipulando todo tipo de productos, materiales o sustancias, peligrosas para la salud, en algunos casos. En este sentido, se ha enfatizado en este artículo, prácticas de trabajo informales, como un recurso último de estas poblaciones marginales, para su supervivencia. De allí que consideramos lo deshumanizador de estas actividades, mereciendo comentarlo un poco más.

Se sabe que la teoría de Marx (1976) relacionada a la comprensión de la lógica de funcionamiento del capitalismo, enfatiza el carácter dependientes de las masas de poblaciones de la ciudad al este sistema de producción, dentro de una lógica explicativa, cuyo sustento ideológico, está en el liberalismo económico y otras de tipo sociológicas, estructurada durante la segunda mitad del siglo XIX. Dentro de esa lógica depredadora, el campesino que vive de la tierra, se ve amenazado y arruinado en muchos casos, ante competencias desleales, sustentadas en leyes hechas por los detentadores del modelo. Al final, muchos de ellos migran a la ciudad, incorporándose a las diversas estructuras laborales existentes (Ver Stavenhagen, 1988; Cambranes, 1992).

Estos grupos migrantes a la fuerza, se suman a los habitantes de la periferia de las ciudades, en tugurios escondidos en las urbes, convirtiéndose en víctimas del sistema económica capitalista. La situación creada por el sistema capitalista, presiona a estos migrantes del interior, y luchan por incorporarse al engranaje del modelo, por medio del mercado laboral formal.

Marx (1976) lo explica como la necesidad que tiene el obrero o campesino de contar con recursos, en este caso dinero que únicamente lo proporciona el estar dentro del sistema. Es un recurso vital suplir necesidades. Así el capitalista aumenta la producción de algún producto ante la necesidad, no tanto de llenar vacíos o carencia de los 
compradores, sino de acumular o multiplicar su capital. Esta lógica, genera puestos de trabajo, y remuneración de los obreros que venden su fuerza de trabajo por medio de un contrato laboral. Quizás se obvio esto que voy a decir, pero es importante recordarlo, este sistema crea un círculo vicioso de dependencia mutua, aunque dentro de la lógica explicativa del modelo, se ve como una especie de "razón social empresarial", ocultando lo inequitativo del mecanismo.

El capitalista, por menor que sea su capital, sea dueño de fábrica o de casas comerciales, siente la necesidad de aumentar sus ganancias, porque esa es la razón de su negocio. No se contenta con obtener ganancias para vivir lo más cómodo posible, por ello busca formas de circular su mercancía, no importando, en muchos casos, si los canales son formales o informales. Este es el caso particular de los mercados libres o populares, donde aparece la categoría del comerciante informal, subordinado a otro que está en el circuito formal.

En base a la cuestión de trabajo como el proceso para la satisfacción de las necesidades, es importante señalar el planteamiento de Maslow (1954) relacionado a la orientación que los individuos hacen ante las necesidades que van experimentando. En otras palabras, el trabajo, en el sentido básico, siempre está orientado a priorizar lo que cada una de las personas necesita, en un continuo organizativo.

De lo anterior, en los mercados urbanos populares, convergen grupos poblaciones provenientes del interior del país que sienten mayor seguridad en estos lugares, para la obtención recursos y llenar sus necesidades básicas de sobrevivencia. El discurso subalterno que ha calado entre los gru- pos que migran, es que en las zonas urbanas se puede progresar con mayor rapidez, Salen de donde antes se encontraba el "nos-otros" y entran a un mundo donde se encuentran los "otros". Siguiendo a Kaustky (1974), el sistema rural es una sociedad "ideal" de perfección porque logra un desarrollo integral de los individuos, al articular medioambiente-hombre-sociedad. Pero todo ese "ideal" se ve frustrado ante la ausencia de políticas públicas que armonicen lo urbano y lo rural.

En cuanto a las relaciones de poder en los espacio de los mercados, Foucault (1984) infiere que

...en las relaciones humanas, sean cuales sean - ya se trata de una comunicación verbal, como la que estamos teniendo ahora, o de relaciones amorosas, institucionales o económicas - el poder está siempre presente: me refiero a cualquier tipo de relación en la que uno intenta dirigir la conducta del otro. Estas relaciones son por tanto relaciones que se pueden encontrar en situaciones distintas y bajo diferentes formas; estas relaciones de poder son relaciones móviles, es decir, pueden modificarse, no están determinadas de una vez por todas... (Concordia)

Por consiguiente, sugiere Foucault, no importa el espacio ni el nivel, las relaciones de poder están presentes explícitamente. Quien domina, no es quien tiene más miembros -hablando como grupo social. En los mercados urbanos con una extensión mayor de 30 manzanas se pueden encontrar más comerciantes ambulantes que fijos o formales. Los comerciantes fijos dominan el mercado por su poder y por consiguiente "estabilidad" económica. 


\section{Conclusiones}

El trabajo como una actividad inherente al ser humano, ha tenido un proceso prolongado de cambios a lo largo de la historia, estableciendo los roles dentro de las sociedades. Ha sido un factor de transformación del medio donde vive el hombre, requeridas por necesidades de mejoras de vida, desde el punto de vista material. De igual forma, ha incidido de manera sustantiva en el pensamiento colectivo de las sociedades, generando divisiones de clase, dentro de una lógica de hegemonía y dominación capitalista.

Ell Mercado Oriental, como mercado libre, popular, es espacio de todos y de nadie. Da alternativa de trabajo a muchas personas. De igual manera es un lugar de permanente conflictos, producto de la precaria organización existente. Si se ordenara

se pudiera tener un mayor control de los espacios y de las dinámicas de mercado que se establecen, principalmente la generada entre comerciantes fijos y ambulantes, entre grandes casas comerciales y pequeños vendedores desplazados a zonas periféricas.

El trabajo en su sentido básico, sin que medien valores de mercado, humaniza. Así lo fue en sociedades simples, miles de años atrás. En este sentido, la emancipación por medio de un trabajo digno y socialmente responsable, es tarea del Estado y de sus ciudadanos. La restitución de los derechos en sociedades desiguales como la nicaragüense, requiere del respaldo de la sociedad a las políticas públicas, y de avances en los niveles de conciencia individual y colectiva.

En el caso del Mercado Oriental, para lograr superar los problemas que lo aquejan, la solución debe de ser integral. La persuasión por medio de programas educativos y de reinserción social, debe de ir acompañado de políticas coactivas. Estas últimas, deben de incidir de manera directa en todos los sectores que convergen, en este gran espacio que es el Mercado, tanto entre los comerciantes fijos como ambulantes (Narváez, Detrás del estigma social: ser comerciante del mercado Oriental de Managua, 2017).

La inclusión de los sectores sociales que interactúan en los mercados, por medio de políticas públicas, incide de manera sustantiva en el trabajo, humanizándolo. La gente debe sentir seguridad donde se encuentran "ganándose la vida", y el proceso de hacer eso, no signifique perderla.

En la actualidad, la idea del trabajo en las sociedades contemporáneas, significa llenar las necesidades planteadas por Abraham Maslow (1954). De alguna manera las compartimos. Se orientan a vender "ideas", o bienes, en un Estado democratizado, donde no exista marginalidad y hacinamiento de las personas; donde el trabajo sea lo más equitativo socialmente hablando, bajo condiciones mínimas de ambiente y salubridad, siendo este el trabajo ideal.

\section{Referencias bibliográficas}

Althusser, L. (1967). Materialismo Dialéctico y Materialismo Histórico. Pensamiento crítico, Habana, Cuba.

Althusser, L. L. (1967). La revolucion teorica de Marx . Mexico: Siglo XXI.

Burlatski. F. (1982). Materialismo histórico. Moscú: Editorial Progreso. 
Bordes, F. (1968). El mundo del hombre cuaternario. Madrid: Ediciones Guadarrama.

Cambranes, J.C. (1992). 500 años de lucha por la tierra,(2 volúmenes). Guatemala: FLACSO.

Concordia, R. (1984). Entrevista con Micehl Foucault: La ética del cuidado de uno mismo como práctica de la libertad. Concordia, 96-116.

Darwin, Ch. (1972). El origen de las especies . (Angela Cardona de Gibert. Ed.). Barceloa: Bruguera)

Giddens, A. (1991). Sociologia . Barcelona : Alianza Editorial.

Harnecker, M. (1976). Los Conceptos elementales del Materialismo histórico. España : Siglo XXI.

Harris, M. (1982). El Materialismo cultural. Madrid: Alianza Editorial.

Kautsky, K. (1974). La cuestión agraria. Etudio de la tendencia de la agricultura moderna y de la política de la socialdemocracia. Barcelona: Editorial Laia.

Lomnitz, L. (1976). Cómo sobreviven los marginados . México: Siglo XXI.

Maslow, A. (1954). Motivación y personalidad . California : Harper .

Marx, C. Engels, F. (1974). Obras escogidas. (3 tomos). Moscú: Editorial Progreso.

Marx, K., Hobsbawm. (1979). Formaciones económicas precapitalistas. Barcelona: Editorial Crítica.

Marx, C. (1976). El Capital. (Traducción de Wenceslao Roces).Bogotá: Fondo de Cultura Económica.
Narváez, N. S. (2017). Detrás del estigma social: ser comerciante del mercado Oriental de Managua. Raices, 32-48.

Petit, et.al. (1978). El modo de producción esclavista. Madrid: Akal Editor.

Quintero, J. (2010). Sobre las teorias de las Necesidades de Maslow. s.c: Reid.

Redfiel, R. (1943). La sociedad Folk. Mexico : Revista Mexicana de Sociologia .

Stavenjagen, R. (1988). Derechos indígenas y derechos humanos en América Latina. México: El Colegio de México. 